\title{
Development of Attachment Theory and Conflicts with Psychoanalysis: Focused on the History
}

\author{
Geon Ho Bahn \\ Department of Psychiatry, College of Medicine, Kyung Hee University, Seoul, Korea
}

\author{
애착이론의 발전과 정신분석과의 갈등: 역사를 중심으로
}

반건호

경희대학교 의과대학 정신건강의학교실

\begin{abstract}
Attachment theory explains normal development and psychopathology in humans based on experience and observation. In particular, the development of attachment between mothers and babies can affect the formation of interpersonal relationships in adulthood beyond latency and adolescence, and the transmission through generations. John Bowlby, who founded the theory of attachment, is a psychiatrist and psychoanalyst. Bowlby was a psychoanalyst certified by the British Psychoanalytical Society, and attachment theory is also rooted in psychoanalysis. In the mid-20th century, Bowlby and orthodox Freudians turned their backs on each other due to theoretical conflicts and factional conflicts between emerging attachment theorists and existing psychoanalysts. Attachment theorists have developed theories through interdisciplinary exchanges, including Harry Harlow's experiments. The recent decline in the status of psychoanalysis has led to the need for a paradigm shift, thus finding an interface with attachment theory as one of the alternatives. Among the reasons why psychoanalysts are interested in attachment theory is that the findings of infant researchers and developmental theorists help explain the psychoanalytic development theory of children. Another issue for convergence is that experts in other fields evaluate the results of experiments and observations based on the ethological approach of attachment theorists as scientific. Despite these changes, it will take a lot of effort to converge attachment theory and psychoanalysis into a new frame.

Psychoanalysis 2021;32(3):65-73
\end{abstract}

KEY WORDS: Attachment theory · Psychoanalysis · Ethology · Strange situation · Frame.

Received: May 17, 2021 Revised: May 29, 2021 Accepted: May 31, 2021

Address for correspondence: Geon Ho Bahn, MD, PhD

Department of Psychiatry, College of Medicine, Kyung Hee University, 23 Kyungheedae-ro, Dongdaemun-gu, Seoul 02447, Korea

Tel: +82-2-958-8542, Fax: +82-2-957-1997, E-mail: mompeian@khu.ac.kr

\section{서 론}

John Bowlby와 동료들은 정통정신분석이론 토대 위에 소 아 관찰과 동물행태학 이론을 접목하여 근거 중심의 새로운 분석이론을 전개하였다(Karen 1998). 전통적 정신분석 이론 에서는 엄마에 대한 아이의 애착을 학습된 이차적 역동으로 보았다(Bemporad 1984). 엄마는 아기의 구강기 필요를 충 족시켜주는 인물이기 때문이다. 그러나 알에서 깨어난 새끼 오리들이 먹이를 주기 전부터 처음 만난 인간을 따라간다든 가, 원숭이 실험에서 음식을 가진 어미 원숭이 모형보다 천

This is an Open Access article distributed under the terms of the Creative Commons Attribution Non-Commercial License (https://creativecommons.org/licenses/by-nc/4.0) which permits unrestricted non-commercial use, distribution, and reproduction in any medium, provided the original work is properly cited.
으로 둘러싼 어미 원숭이 모형을 선호하는 등, 애착 행동은 인간을 포함한 생물체의 공통된 특징이며 일차적이고 독립 적 발달 경과라는 주장이 등장하였다(Karen 1998). Bowlby 의 이론은 애착이론이라는 새로운 발달 이론으로 발전하였 다. 기존 정신분석 이론이 무의식과 방어기제를 중심으로 개 인 내부의 역동을 중시한 반면, 애착 이론에서는 아기와 엄 마의 양자간 상호작용을 강조하였다(Karen 1998). 이러한 활 동은 Bowlby와 기존 정신분석가들 사이에 심각한 갈등을 초 래하였고, 20세기 후반 결별하였다.

정신분석은 오랫동안 정신과 영역에서 영향력 있는 정신 병리 이론이었으며, 정신장애의 치료기법이었다. 그러나 정 신분석 이론을 지지할 수 있는 견고하고 설득력 있는 과학적 근거 부족으로 오늘날 정신분석은 변방으로 밀려나고 있다 (Paris 2017). 정통 정신분석 치료 전후의 결과에 대한 논문들 
의 메타분석 결과, 정신분석 기법은 복합적 정신장애에 효과 적인 것으로 평가되었으나, 치료효과를 비교할 만한 대조군 과 대조치료기법이 없다는 점에서 결과 해석에 심각한 제한 이 따른다(de Maat 등 2013). 연구 표본의 이질적 임상 증상, 작은 표본 수, 낮은 효과 크기 등으로 인해 효과적 치료법이라 는 평가 결과의 정당성을 확보하지 못하고 있다(Thombs 등 2011). 이처럼 정신분석 치료에 할애하는 시간과 비용 대비 효 용성에 대한 근거 불충분으로 정신과 영역에서 입지가 축소 되었으며, 그 틈은 인지행동치료와 같은 다양한 치료 기법들 이 차지하게 되었다. 정신분석가였던 Aaron Beck이 창시한 인지행동치료는 오늘날 가장 영향력 있는 정신과 영역의 치 료법 중 하나이다(Paris 2017). 정신분석 이론이 여전히 인간 정신의 이해와 문제 해결에 핵심이론임은 분명하지만, 혹독 한 임상 현장에서 살아남기 위해서는 '현재, 여기'에 맞춘 정 신분석의 패러다임 변화가 절실하다는 주장에 힘이 실리고 있다(Cortina 2016). 그런 점에서 경험에 근거한 자료 외에 연구 결과를 중시하였던 Bowlby의 애착이론은 패러다임 수 정 설계에 유용한 이론 중 하나이다.

본 논문에서는 새롭게 부각되고 있는 애착이론과 정신분 석의 수렴 관련 변화를 이해하기 위한 기초 작업으로 애착 이론의 발전 과정과 정신분석학계와의 갈등에 대한 역사를 재조명하였다.

\section{애착이론의 발달}

\section{애착의 정의와 초기 발달 과정}

애착이란 우리의 삶에서 특별한 사람에 대하여 느끼는 감 정적 또는 정서적 연결이다(Bowlby 1969). 애착은 아기와 돌 보는 이가 서로 따뜻하게, 친밀하게, 지속적으로 관계를 가지 며, 그 관계 속에서 만족스럽고 즐거울 때 발생한다. 궁극적 으로 애착을 이루고자 하는 대상 인물과 가까워지고 싶어하 는 것이며, 심리적으로 애착의 목표는 애착 대상의 존재하에 안정감을 취하는 것이며, 생리적으로는 생존을 목표로 한다. 애착행동의 기능적 의미는 첫째, 근접성, 즉, 애착 대상과 접 촉하고 관계 유지, 둘째, 분리 저항, 즉, 애착인물과 분리됨에 대한 반항, 셋째, 안전 기지, 즉, 애착 대상 인물을 중심으로 주변 환경과 주변 인물을 탐색하고 접근하기 위한 근거지 역 할, 넷째, 안전한 항구, 즉, 난관에 부딪히거나 지원이 필요할 때 재충전을 위해 돌아갈 수 있는 곳 등이다(Feeney와 Noller 1996). 이러한 애착이론의 발달은 이론의 창시자인 Bowlby 의 개인력과 밀접한 관련이 있다. Bowlby의 개인력과 공동 연구자들 관련 자료는 이전 논문(Bahn 2013)에 발표된 바 있다. 1930 40년대 애착이론 초기 연구는 비행청소년과 그
들 가족의 문제, 특히 어머니의 부재에 대한 결과를 분석한 논문 "Forty-Four Juvenile Thieves: Their Characteristics and Home Life”로 압축할 수 있다(Bowlby 1944).

\section{Bowlby의 영국정신분석학회 활동}

Bowlby는 Melanie Klein의 친밀한 동료이자 추종자인 Joan Riviere에게 개인분석을 받았으며, 1937년 정신분석가 자격을 취득하였고 영국정신분석학회(The British PsychoAnalytical Society)의 일원이 된다(Karen 1998). Riviere는 Bowlby와 잘 맞지 않았던 것 같다. 그녀는 Bowlby가 긁어 부스럼을 만들려고 노력하는 사람처럼 분석 이론에 대해 질 문을 너무 많이 하였고, 분석에 진전이 없어서 힘들어하였 다. 하지만 Bowlby는 자기 아내에게 Riviere에 대해 거의 이 야기하지 않았다. Ursula Bowlby가 들은 유일한 내용은 "그 녀는 나처럼 상류층 출신의 숙녀이다”였다. 이후 Melanie Klein에게서 아동정신분석 사례 지도감독을 받았다. 당시 그 는 기존 정신분석 이론 대신, 환경과 양육인자의 중요성 및 어머니와 아이의 실제 관계를 더 중시하였으며, 그러한 태도 는 Anna Freud 계열 분석가들은 물론 Melanie Klein 계열 분 석가들과 갈등의 뿌리가 된다. Anna Freud와의 빈번한 충돌 에도 불구하고 그는 1944 1947년 동안 영국정신분석학회에 서 수련 업무(training secretary)를 담당하였고, 1957 1961년 은 영국정신분석학회 회장에 취임한 Donald Winnicott를 도 와 부회장으로 활약하였다(Karen 1998).

2차 세계대전 중에는 군의관으로 근무하며 통계와 정신분 석 이론을 적용하여 장교 선발 업무를 수행하였다(Holmes 1993). 당시 관계자들은 Bowlby의 탁월한 업무 능력을 높이 평가하였다. 1946년 2월, 평생 그의 연구 터전이 된 Tavistock Clinic에서 소아분과 개설 업무를 맡고 근무를 시작한다. 임상 진료, 수련프로그램, 그리고 연구 등 세 가지 영역 중 연구부 문은 1948년 Sir Halley Stewart Trust로부터 연구기금을 받으 면서 본격적으로 시작된다(Karen 1998). 연구 내용 중 부모와 분리된 아이들을 관찰하는 일을 담당할 정신사회복지사를 채용하게 되는데, 마침 정신사회복지사 자격을 취득한 Anna Freud의 제자였던 James Robertson이 지원하면서 두 사람 이 만나게 된다(두 사람이 함께 했던 연구들에 대해서는 뒤 에 나오는 James Robertson 편에서 소개한다).

전쟁이 끝난 뒤 유럽에서만도 1,300 여만 명에 이르는 전쟁 고아와 집 잃은 아이들의 정신건강에 관심이 쏠렸다. World Health Organization(WHO)에서는 이러한 아동들에 대한 연 구프로젝트를 준비하면서, 전시에 보여준 Bowlby의 뛰어난 추진력과 전쟁 전 수행한 기존 연구를 감안하여 그를 이 프로 젝트의 자문책임자(consultant)로 선정하였다(van der Horst 
등 2020). 전쟁피해 아동에 대한 프로젝트가 조성되는 데 기 여한 중요한 요인 중 하나는 Hampstead Wartime Nursery 보 고서였다(Freud 1973). Anna Freud와 Dorothy Burlingham 이 2차 세계대전 중 이 전시 탁아소에서 런던 공습 피해 아 동이나 전쟁고아들을 돌보며 작성한 일지 형식의 보고서는 이들 아동에 대한 체계적 관리와 대책의 필요성을 담고 있 다(van der Horst 등 2020). WHO Mental Health Section의 수장이며 Bowlby의 의과대학 동문이기도 한 Ronald Hargreaves(1908 1962)가 이 과정에서 징검다리 역할을 했다.

WHO 프로젝트 자문책임자로 활동하는 동안 Bowlby는 6주간 유럽 대륙의 프랑스, 네덜란드, 스웨덴, 스위스를 방문 하였다. 이후 5 주간 미국을 방문하여 관련 기관을 둘러보고, 사회사업가 및 소아정신과 의사들과 정보를 교환하였다 (Karen 1998). David Levy, William Goldfarb, Milton Senn, Reńe Spitz 등과 교류하며 그들의 문헌을 검토할 기회를 갖기 도 하였다. 이러한 자료와 제안을 담아 "Maternal Care and Mental Health'라는 기념비적인 WHO 보고서를 출판하였다 (Bowlby 1951). 이 프로젝트 동안 Bowlby는 아기와 엄마의 상호작용과 엄마의 돌봄의 중요성을 확인할 수 있었다. 아기 와 엄마의 조기 분리는 아기에게 심각한 해를 끼칠 수 있으며, 결과적으로 사회에 피해를 끼칠 수 있다고 주장하였다. 따라 서 이러한 아동과 가정을 지원하기 위한 기금 마련의 필요성 을 역설하였다. 결혼하는 신혼 부부에게도 모자 상호작용 교 육이 필요하다고도 하였다. 하지만 많은 사회복지사나 전문가 들은 그의 이론과 정책에 반대하였다. Bowlby는 어린 아기에 게 투자하는 것이 나중에 정신증상 발병 후 수용 시설 설치, 비행청소년이나 범죄자 수용소 등에 들어가는 비용보다 횔씬 적다는 것을 강조하였으나 이해하는 사람은 많지 않았다.

단, Bowlby는 모자 연계에 대한 자신의 이론을 전파하고 확장하는 데 힘쓰는 한편, 자기 이론에 유리하지 않은 정보 나 자료를 무시하기도 하였다. 즉, 엄마-아기 관계는 서로의 상관관계만을 인정할 수 있으며, 빈곤, 굶주림 같은 환경요 인과의 상호작용을 인정하는 않는 우를 범한다. 이 보고서는 Bowlby 개인은 물론 그의 이론을 세계적으로 인정받게 만드 는 계기가 된다. 하지만, 보고서 내용 중 Bowlby가 개인적 과 욕을 부렸던 부분은 계속 비판의 대상이 되며, 결국 10 년 뒤 WHO는 Mary Ainsworth 팀에게 십 년 전 Bowlby가 했던 작업을 재시행하도록 의뢰하였다(van der Horst 등 2020).

\section{애착이론 발전에 기여한 인물}

\section{Ronald Hargreaves(1908 1962)}

Hargreaves는 Bowlby와 같은 University College London
에서 의과대학을 마쳤다. 정신의학을 공부하였으며 1938년 부터 Tavistock Clinic에서 근무하다가 2차 세계대전이 발발 하자 군의관으로 복무하였다. 전쟁 후 다시 Tavistock Clinic 으로 복귀하였으나, 1948년 $\mathrm{WHO}$ 에 개설된 정신건강 부서의 수장으로 옮겨서 1955년까지 근무한다(Hargreaves 1963). 이 기간 동안 $\mathrm{WHO}$ 의 부모를 읽은 아이들(homeless children) 정신건강 프로젝트를 Bowlby에게 맡기게 된다. Hargreaves는 이미 Bowlby의 연구에 대해 알고 있었고, 군의관 시절에도 만 난 적이 있었으며, $\mathrm{WHO}$ 에서 진행하는 청소년 비행연구를 부 탁했다가 거절당한 적도 있었다(Karen 1998). WHO 프로젝트 설계 시 Bowlby가 적임자라고 적극 추천한 것으로 알려져 있 고, Bowlby도 과거 한 차례 거절한 적이 있었기에 아동 정신 건강 프로젝트를 받아들였다고 한다. 그 후 두 사람은 물론 가 족끼리도 자주 만나는 친한 사이가 되었다(van der Horst 2020). 1955년 WHO를 사직하고 The University of Leeds에 정신과 교수로 부임하였고, 그곳에서 Max Hamilton과 함께 클로르프로마진 약물 시험에 참여하였으며, Hamilton과 함 께 Hamilton Anxiety Rating Scale(HAM-A), Hamilton Depression Rating Scale(HAM-D) 같은 정신건강 평가 척도를 여러 개 개발하였다. 1962년 초, 마취과 의사였던 아내가 먼저 사망하였고, Hargreaves도 같은 해 말, 수술 후 사망하였다.

\section{애착이론의 공동연구자}

James Robertson(1911 1988), Joyce Robertson(1919 2013)

James Robertson은 스코틀랜드의 가난한 노동자 가정에 서 일곱 형제와 함께 자랐다. 가난했지만 그의 부모는 자녀 를 항상 따뜻하게 돌봐주는 분들이었다. 훗날 그는 이러한 부모의 훌륭한 양육태도가 어려운 환경에서도 항상 미래를 위해 열심히 노력하는 자신을 만들어 주었다고 회상하였다 (van der Horst와 van der Veer 2009). 14 28세까지 공장에 서 일하며 독학과 야학으로 공부를 이어갔다. 2차 세계 대전 이 터지자 퀘이커 교도인 그는 런던에서 사회봉사로 군 징집 을 대신하였다. 1941년부터 Hampstead Wartime Nursery에 서 근무하게 되었고, 그곳에서 일하던 Joyce를 만나 결혼하 기에 이른다. 당시 전시탁아소를 운영하던 Anna Freud는 모 든 직원들에게 수용된 아이들의 행동 관찰 내용을 보고하도 록 하였는데, Robertson의 보고서를 통해 그의 재능을 알아 보았고 그에게 계속 공부하도록 권한다. 1947년 정신사회복 지사 자격을 취득하고 Anna Freud에게 개인분석을 받기 시 작한다. 1948년 Tavistock Clinic에서 Bowlby의 연구보조를 맡는다. 요양원 연구(sanatorium study)라고 불리는 이 연구 
는 병원에 입원하거나 탁아소에서 부모와 떨어져 지내는 1 3세 아이들이 대상이었고, Robertson의 임무는 이들 아이 들의 행동관찰보고서 작성이었다. 그의 관찰 내용을 토대로 Bowlby는 부모와 분리된 아이들이 저항-절망-거부(protest-despair-denial)의 단계를 보인다고 보고하였다(van der Horst와 van der Veer 2009). 같은 해 Robertson은 본인 인 생은 물론 애착이론의 미래를 바꾸는 큰일을 해낸다. 탈장 수술을 받기 위해 병원에 입원하는 Laura라는 두 살짜리 여 자아이의 병원 생활을 자비로 구입한 카메라로 촬영한다. "A Two-Year-Old Goes to Hospital”이라는 영화를 통해 부모 와 분리된 아기의 3단계 반응을 시각적으로 증명하는 엄청난 작업이었다(Robertson 1952).

Bowlby와 Robertson은 오랜 기간 서로 협조하면서 조화 를 이루며 지냈다. 이 둘의 업적은 현재까지도 발달심리학 분 야에서 큰 영향을 미치고 있다. 그러나 1950년대 말까지 평화 롭던 두 사람의 공조 체계는 1960년 Bowlby와 Anna Freud 계열 분석가들과의 논문 사건 이후 크게 흔들린다. Bowlby 는 1960년 'The Psychoanalytic Study of the Child'에 게재한 논문에서 두 가지 측면에서 Anna Freud의 이론을 반박한다 (Bowlby 1960). Bowlby의 논문에 대해 Anna Freud와 그녀 를 지지하는 분석가들의 논문이 같은 호에 실렸고, 이 사건은 Bowlby와 정신분석학계와의 결별을 초래한다. Anna Freud 는 Bowlby와의 결별 과정에서 Robertson을 자기 쪽으로 서 도록 회유하였고, 이 일로 Robertson과 Bowlby의 관계에도 금이 간다(van der Horst와 van der Veer 2009). 당시 Robertson은 자신이 고안하고 입증한 '저항-절망-거부(탈착)'로 이어지는 분리 반응 이론을 Bowlby가 독차지하는 것에 불만 을 가지고 있었던 것도 이 둘의 관계가 취약해진 원인이 된다. Bowlby는 그의 역할을 단지 자료 수집 정도로만 여겼으나, Robertson은 분석가이자 이론가로서의 입장을 인정받고자 했 다. 후대 역사가들은 두 사람 사이의 사회적 신분 차이 역시 분쟁의 소인이 되었을 것으로 추정하였다(van der Horst와 Van der Veer 2009). 이후 Bowlby는 Robertson에게 연구나 연구비를 배정하지 않았고, Robertson 역시 공개적으로 Bowlby에게 자신의 연구에 대한 입장을 내세우게 된다. 이 둘 사이의 관계는 죽을 때까지 서로 말도 하지 않고 지내는 사이 가 되었으며, Robertson의 아내는 심지어 Bowlby 장례식에서 조사를 할 예정이었던 Ainsworth에게 남편의 이름을 언급하지 말아달라고 할 정도였다(van der Horst와 Van der Veer 2009). Joyce User(훗날 결혼 후 Joyce Robertson)는 1919년 런 던에서 출생하였고, 1941년 2차 세계 대전 중 Anan Freud와 Dorothy Tiffany Burlingham이 운영하던 Hampstead Wartime Nursery에 참여하였고, 그곳에서 James Robertson을
만나 결혼한다. 당시 James는 탁아소의 난방과 여러 가지 잡 무를 맡고 있었다. 결혼 후 두 딸을 낳았고, 애들이 커서 학교 에 다니게 되면서 Joyce도 1957년 Anna Freud Center에서 일하기 시작하였고, Anna Freud의 격려로 자기 분야의 논문 을 쓰게 되었다. Tavistock Clinic에서 1975년 은퇴한 뒤 남편 과 함께 Robertson Center를 설립하여 자신들이 제작한 필름 을 상영하고 교육과 법원 가족 담당 부서의 전문가로 활동하 였다. Anna Freud와 Dorothy Tiffany Burlingham 역시 그들 센터의 창립 회원이었고, 모임에 참석하였다(Lindsay 2013).

\section{Mary Ainsworth(1913 1999)}

Mary Dinsworth Salter는 1913년 미국 오하이오에서 중 산층 가정의 세 딸 중 장녀로 태어났고, 캐나다 토론토에서 자랐다. 1929년 토론토 대학 입학 후 인생의 첫 번째 멘토인 William Blatz 교수의 심리학 강좌 때 들었던 '안전 이론(security theory)'은 그녀의 평생 연구 주제가 된다(Karen 1998). 2차 대전 발발 후 군에 입대하여 4년 간 복무한 뒤 모교에 돌 아가 Blatz 교수팀에 합류한다. 1950년 심리학을 전공하던 Len Ainsworth와 결혼 후 남편의 학위 과정을 위해 영국으 로 갔고, 그곳에서 Bowlby의 연구원으로 일하게 된다. 그녀 를 면접한 Bowlby는 그녀야말로 자신의 연구에 꼭 맞는 인 물임을 알아보았다. 명석하고, 섬세하며, 독자적 사고가 가능 하고, 정확한 자료 해석 능력이 있다고 평가하였다. 그녀는 당시 함께 일하던 Robertson의 관찰 방식, 즉 자연스러운 환 경에서의 직접 관찰을 선호하였다. 1954년 Tavistock Clinic 에서의 3년 반을 보내고 Makerere College of Uganda에 직 장을 얻은 남편을 따라 우간다로 간다. 척박한 곳이었으나 28 명의 신생아를 대상으로 자신만의 자연스러운 관찰 연구 를 시작한다. Makerere 대학 내 The East African Institute of Social Research에서 소규모 연구 자금을 받았고, 한 아이 에 대해 9 개월간 2주 간격으로 아기의 집을 방문하였고, 매 방문 시 두 시간씩 통역을 맡은 Kati Kibuka가 엄마와 대화 를 나누는 동안 아기를 '자연스러운 환경에서 직접 관찰'하 는 방식이었다. 1930년대 초 시작된 유아 연구는 생후 첫 3년 기간을 관찰한 Jean Piaget를 제외하면 대부분 네 살 이상의 아이들을 대상으로 하고 있었다. Ainsworth는 수유방법, 손 가락 빨기, 목욕, 청결상태, 배변훈련, 수면 환경, 아기를 안 고 옮기는 방법, 자위행위, 스트레스반응, 분노, 울기, 지시 따 르기, 체벌, 의학적 처치 등 모든 것을 관찰하고 기록하고 분 석하면서 "어떻게 애착이 생겨나는지? 어떤 요소가 애착을 촉진시키고 저해하는지? 애착이 발생한 것을 어떻게 판단하 는지?"에 대한 답을 찾기 위해 노력하였다(Ainsworth 1967).

1956년, 남편을 따라 미국 Baltimore로 돌아온다. 이후 
Johns Hopkins University에서 연구를 이어간다(Karen 1998). 1960년 Bowlby가 그녀를 방문하고 우간다에서의 연구 결과 에 대해 토론하였다. Bowlby는 그녀가 진행한 연구의 독창 성과 우수함을 인정하였고, 이제 그녀는 Bowlby의 연구원에 서 함께 연구를 이어가는 공동연구자 반열에 올랐다. 대학에 서 발달심리학 강의를 진행하면서 Inge Bretherton, Everett Waters, Mary Main 같은 훗날 발달심리학계를 이끌게 될 제 자들도 양성하였다. University of Minnesota의 젊은 조교수 였던 Alan Sroufe는 Ainsworth의 연구방식을 도입하였다. 1961년부터 그녀는 본격적으로 발달심리학 연구에 몰입할 수 있었고, 1963년 연구비를 받아서 자신이 가장 하고 싶었던 영유아발달 연구를 진행하였다. 1963 1967년간 진행된 연구 의 결과물이 'Strange Situation Procedure'이다(Ainsworth 등 1978). Ainsworth는 이 연구를 통해 현재 우리가 알고 있는 애착 유형을 분류하였다. Ainsworth는 안정애착과 불안정 애착(insecure attachment)으로 명명하였으나, Bowlby는 불 안정애착 대신 불안애착(anxious attachment)을 제안하였 다. 그 이유는 자신이 여전히 정신분석가이며 애착이론도 정 신분석에 뿌리를 둔 이론임을 알리고 싶어했기 때문인 듯하 다(Karen 1998). Ainsworth는 그의 제안을 받아들였으며, 오늘날 두 용어는 혼용되고 있다. 불안정애착은 회피형 애착 (avoidant attachment)과 양가적 애착(ambivalent attachment)을 포함한다. 1990년 Mary Main은 불안정애착의 또 다른 형태인 비조직화 애착(disorganized attachment)을 추 가하였다(Main과 Solomon 1990).

1961년 WHO에서는 십 년 전 Bowlby가 수행한 프로젝트 보고서에서 모성박탈(maternal deprivation)의 문제를 제시 하여 평지풍파를 일으킨 데 대한 후속 검증 연구를 진행하기 로 결정한다(Karen 1998). 소아과 의사인 Dane Prugh, 문화 인류학자인 Margaret Mead, 동물행태학자인 Harry Harlow 등이 연구에 참여하였다. 사업에 대해 전해들은 Bowlby는 과거 함께 일했고 당시 미국에서 일하던 Mary Ainsworth에 게 연구에 합류하도록 부탁하였다. 연구진은 그간 진행된 많 은 관련 연구자료를 분석하여 '모성박탈'의 종류를 모성돌봄 의 결핍(부족), 모성돌봄의 왜곡(방치 또는 학대), 모성돌봄 의 중단(분리, 돌봐주는 사람이 바뀜) 등 세 가지로 분류하였 다. 모성박탈은 상황과 형태에 따라 결과가 달라질 수 있으 며, 변수를 계산하기가 쉽지 않다고 보고하였다. 결론적으로 십 년 전 Bowlby의 연구는 문제가 없으며 그의 제안 역시 일 리가 있다고 결론내렸다(Ainsworth 등 1962). Ainsworth는 1975년, University of Virginia로 옮겼고, 그곳에서 1992년까 지 활발한 연구 생활을 지속하였다.

\section{동물행태학과의 인연}

Bowlby의 애착이론이 과학적으로 인정받게 된 데는 두 사 람의 동물생태학자를 빼놓을 수 없다(van der Horst 등 2007). 오스트리아의 Konrad Lorenz(1903 1989)와 미국의 Harry Harlow(1905 1981)이다. Lorenz는 어릴 때부터 동물을 좋아 했으며 평생 자신이 좋아하는 동물의 행태 연구에 몰두하였 다. 거위들이 알을 깨고 나오면서 처음 만나는 인물을 따르는 행동을 통해 음식이나 물과 같은 생리적 충족보다 우선하는 상호작용이 있음을 증명하였고, 이를 각인(imprinting)이라고 명명하였다. 동료인 Niko Tinbergen과 Karl von Frisch와 함께 '개인과 사회의 행동 양상'을 주제로 1973년 노벨 의학 상을 수상하였다.

1951년 여름, Bowlby는 젊은 심리학자 Norman Hotoph 로부터 Lorenz라는 학자의 각인 이론이 정서적 연대감 형성 과 관련된 과정을 설명하는 이론이라는 이야기를 들었다. 즉 시 'Der Kumpan in der Umwelt des Vogels(the companion in the bird's world)'(Lorenz 1935) 논문을 구해 읽었고, 논문 을 통해 '강한 연대감, 먹이와 상관없이 빠르고 강력하게 일 어남'이라는 각인의 정의에 Bowlby 자신이 각인될 정도였다 (Karen 1998). 1951 1952년 사이에 많은 동물생태학 서적을 읽었고, 1953 1956년 진행된 $\mathrm{WHO}$ 연구 모임에서 두 사람은 조우한다. 두 사람은 서로의 연구 분야에 대해 의견을 교환하 였고, 각자 연구에 반영하였다.

Harlow와 Bowlby는 만나기 전부터 서로의 연구에 대하여 잘 알고 있었으나, 실제 만남은 영국 동물행태학자인 Robert Hinde가 Harlow에게 Bowlby를 소개하면서 이루어졌다 (Suomi 등 2008). Hinde는 원래 조류의 노래 학습에 대한 연 구를 하였으나 Harlow를 만나면서부터 그의 영향을 받아서 원숭이에서의 유아-엄마 상호작용으로 연구주제를 바꿨다. Hinde의 연구 주제는 Bowlby의 관심을 끌었고, 그런 연유 로 Hinde는 두 사람을 연결해 주었다. 이들 세 사람은 이후 Bowlby가 주최하는 Ciba-Foundation 모임에서 자주 만나 의견을 교환하였다. 1950년대 말부터 시작된 Bowlby와 Harlow의 교류는 1974년 Harlow가 은퇴할 때까지 이어졌고, 그 후에는 Harlow의 대학원생이었고 훗날 Harlow의 연구를 이 어가게 된 Stephen Suomi와 Bowlby의 교류가 지속된다.

Harlow는 1930년 Stanford 대학에서 박사학위를 받고 곧 바로 University of Wisconsin-Madison에 조교수로 발령받 았다(van der Horst 등 2008). 쥐 동물실험실 폐쇄로 영장류 를 대상으로 연구를 계속하게 되었으나, 비용 및 실험동물 간 감염 등의 문제가 발생하였다. 이를 해결하기 위해 Harlow의 영장류 실험실에서는 새끼가 태어나면 어미와 분리 해서 독방에서 키우는 방법을 사용하게 되었다. 고립된 채로 
성장한 원숭이는 신체는 건강하였으나, 이상한 상동행동과 사회성 발달 지연을 보였다. 위생과 청소를 위해 우리에 넣어 둔 헝겊으로 만든 깔개를 교체하려고 할 때마다 원숭이가 심 하게 저항하는 것도 관찰할 수 있었다. Harlow의 실험실에서 박사 후 과정을 밟고 있던 Bill Mason은 원숭이들이 깔개에 서 많은 시간을 보내는 것에 주목하였다. Harlow와 Mason은 이 점에 착안하여 음식과 물통을 매단 철사로 형체를 만든 어 미 원숭이와 음식이나 물이 없이 천으로 철사틀을 감싼 어미 원숭이를 만들고 새끼 원숭이의 행동을 관찰하였다.

이 연구는 Lorenz의 각인 이론과 마찬가지로 음식이 아기 와 엄마의 일차적 애착 매개체라는 정신분석 이론을 반박하 는 데 기여하였다(Suomi 등 2008). 1958년 4월 26일 Bowlby 는 Harlow의 실험실을 방문하였고, 고립된 채 성장한 새끼 원숭이들의 행동을 관찰하며 인간에서도 아기와 엄마의 장 기간 분리는 사회성 발달에 영향을 미칠 수 있으며, 이는 평 생 지속될 수 있음을 알게 되었다(van Rosmalen 등 2020). Harlow의 연구는 Bowlby의 이론 수립에 생물학적 기초를 제공한 가장 중요한 실험이었다. 애착이론의 안전기지 $\left(\mathrm{se}^{-}\right.$ cure base) 개념(Bowlby 1988) 역시 Harlow의 실험 중 하나 와 관련 있다(Suomi 등 2008). 실험의 구성은 장난감과 여러 가지 흥미로운 물건들을 넣어 둔 놀이방에 새끼 원숭이와 천으로 만든 어미 원숭이를 집어넣는 것이다. 놀이방에 들어 가자마자 새끼는 미친 듯이 어미 원숭이 모형에 매달리지만, 시간이 가면서 차츰 어미를 떠나 잠깐씩 장난감이나 사물을 만지고는 곧바로 어미에게 돌아온다. 이러한 동작을 반복하 면서 어미를 떠나는 시간이 늘어난다. 하지만 다시 어미에게 로 돌아간다. 이 과정에서 어미는 안전기지 역할을 하는 것 이다. Margaret Mahler의 분리개별화 이론에서 인간의 아기 가 연습(practicing)과 화해(rapprochement) 단계를 거치는 것과 비슷하며, 대상항상성이 생기기 전까지는 아기가 엄마 에게 돌아가는 것은 이러한 안전기지 개념과 비슷하다(Bahn 2021).

\section{정신분석학계와의 갈등}

\section{정신분석이론과 애착이론의 차이}

1940년대 후반 Tavistock Clinic에서 Anna Freud, Bowlby, James Robertson은 함께 근무하였다. 당시 아이들을 관찰한 내용을 이야기할 때는 대개 서로 의견이 일치하였으나, 결과 에 대해서는 서로 다른 해석을 내리곤 했다(van der Horst와 van der Veer 2009). 실무에 대해서는 서로 불만이 없었으 나, 이론에 관해서는 종종 의견 불일치가 나타났고 점차 더 잦아졌다.
1951년 발표한 WHO 보고서, 'Maternal Care and Mental Health'(Bowlby 1951)는 아동의 정신건강과 부모의 양육태 도에 대해 엄청난 파장을 불러일으켰다. 보고서 내용 중 정통 정신분석이론과 크게 배치되는 내용들 때문에 정신분석계의 반발을 불러왔다. Bowlby는 Klein 계열의 정신분석 수련 과 정 중에도 아이와 엄마의 정서적 관계를 설명하는 "cupboard love' 또는 '이차 역동 이론(theory of secondary drive)'을 수 용하지 않았었다. WHO 보고서에도 이 부분에 대해 오히려 아이와 엄마의 관계는 독립적이고 일차적 역동이라고 기술하 였다. 하지만 당시 보고서 내용을 입증할 만한 근거가 충분치 못한 점도 비난 받는 원인이 되었다. 예를 들어 Winnicott은 어머니의 돌봄이 아이에게 어떻게 영향을 주는 것인지, 어떤 심리 과정이 작동하는 것인지 설명을 요구하였으나 Bowlby 는 이에 대해 제대로 답변을 할 수 없었고, 훗날 동물행태학 에서 답을 구하게 된다(van der Horst 등 2007).

분석가로서 Bowlby의 행보는 계속 순조롭지 않았다(Karen 1998). 앞서 소개한 것처럼 Bowlby는 Anna Freud가 이 끄는 기존 정신분석계와 파벌 간 갈등은 물론 이론적으로도 충돌의 소지가 많았다. Bowlby가 Klein 계열 분석가에게 분 석 받고 사례 지도감독을 받았으나 그들에게 좋은 인상을 주 지 못했음에도 Klein 계열로 분류되고 있었고, 이론적으로도 충돌하고 있었다. 특히 Konrad Lorenz나 Harry Harlow 등 의 동물행태학 연구결과를 인간 이해에 도입한 것은 당시로 서는 매우 획기적이었으나, 동물 연구를 인간에 적용한 것이 정신분석계의 반발을 초래하였다. Bowlby는 인간과 동물의 행동은 기본적으로 호르몬, 중추신경계의 특징, 환경 자극 등에 의해 결정되며, 이는 기계적 시스템과 유사하다고 정의 하였다(Bowlby 1969).

Bowlby가 정신분석계와 등지게 된 몇 가지 구체적 삽화 를 제시한다. 아기가 어머니를 필요로 하는 것이 배고플 때 젖을 주기 때문이며, 따라서 아기는 어머니가 자기를 충족시 켜주는 인물임을 알게 되고 어머니에게 애착을 갖게 된다는 정신분석 이론에 대해 Bowlby는 '대상관계의 찬장 사랑 이 론(cupboard love theory of object relations)'이라며 반박하 였다. Lorenz나 Harlow의 동물실험에서처럼 인간이나 동물 은 배고픔 때문에 어머니에 대해 애착이 생겨나는 것이 아 니며, 애착에 필요한 요인 중 하나는 피부 접촉(따뜻함, 촉감 등)이라고 주장하였다(Bowlby 1969). 또한 인간의 생리를 설명하기 위해 당시로는 획기적인 인공두뇌적 피드백 모델 (cybernetic feedback model)을 도입하였다. 이 모델을 설명 하기 위해 '자동 방 온도 조절기' 개념을 예로 들었다. 즉, 방 온도가 올라가면(자극) 수용체가 이를 감지하고(input) 중앙 에 신호를 보내며, 조절기는 온도를 자동으로 낮추는 반응 
(output)을 전달한다. 이처럼 자동으로 온도를 감지하고 조 절하는 되먹이기 체계(feedback loop)를 통해 원치 않는 결 과를 조율한다(self-regulation)(Bowlby 1969). 이러한 설명 은 분석가들이 보기에 무의식 개념이나 타협형성 같은 기전 을 무시한 것이며, 인간 행동을 기계적으로 설명하는 것은 부 적절하다고 비난하였다.

성 발달 이론에 대한 입장 차이도 고려해 볼 수 있다. 정신 분석에서는 인간의 성 본능은 재생산 기능뿐 아니라 특별한 쾌감을 얻는 목적이 있다고 주장하였으나, Bowlby는 성 행 동의 유일한 기능은 종족보존의 생물학적 기능이라고 주장 하면서 Freud의 정신성발달이론 발견을 무시하였다(Bowlby 1973).

\section{Bowlby와 정신분석계의 결별}

결별의 도화선이 된 계기 중 Bowlby가 1960년 'The Psychoanalytic Study of the Childa'에 게재한 논문에 대한 '프 로이드 학파의 기습(Freudian assault)' 사건을 들 수 있다 (Cortina와 Marrone 2004). Bowlby가 게재한 논문의 내용은 Robertson의 관찰을 토대로 Bowlby가 작성한 것으로, 엄마 가 없어지면 어린 아이들조차 애도(mourn)를 보이고 이 슬 픔(grief)은 오래 지속된다고 하였다(Bowlby 1960). 이 논문 에서 Bowlby는 애도와 슬픔에 대한 기존 정신분석 이론이 그다지 유용하지 않다고 주장하였다. 우선, 아이의 슬픔이 36 48 시간 정도로 짧게 지속된다고 한 Burlingham과 Anna Freud의 의견은 분명히 옳지 않다고 기술하였다. 또한 아이 의 슬픔은 엄마의 유방을 상실했기 때문이 아니고 사랑하는 사람(whole person)을 상실했기 때문이라고 주장하였다. 이 러한 정신분석 이론에 대한 반박은 Anna Freud를 포함한 다른 분석가들에게는 큰 충격이었다. 학술지의 간행위원이 었던 Anna Freud는 같은 호에 게재한 반박 논문을 “그녀의 팀과 Bowlby의 팀 모두에게 (논문의 내용에 나오는 아이들 의 행동을 관찰한)Robertson은 소중하고 중요한 존재”라며 Robertson을 추켜세우는 내용으로 시작한다(Freud 1960). 그러면서 엄마와 분리된 어린 아이는 대리모의 돌봄을 받게 되면 슬픔이 거의 없거나 횔씬 적을 것이라고 추정하였다. 분리에 따른 슬픔은 불가피하다는 Bowlby의 주장은 증명된 바 없다고 하였다. 다른 두 편의 이어진 반박 논문에서 Schur(1960)와 Spitz(1960) 역시 Bowlby가 정신분석 이론을 제 대로 이해하지 못해서 생긴 결과라고 폄훼하였다. 같은 호에 게재된 이러한 '프로이트 학파의 기습'에 대해 Bowlby는 제 대로 대응할 수 없었다. 이 기습 작전의 배후에 누가 있었는

${ }^{a}$ 이 학술지는 1945년 Anna Freud, Heinz Hartmann, Ernst Kris가 창간하였고, 연 1회 발행하였으며, 현재도 발행되고 있음.
지는 명확하지 않다. 다만, 자신의 관찰 보고서를 토대로 Anna Freud를 반박한 Bowlby 때문에 Robertson의 입장이 난처해졌을 것은 분명하다. Anna Freud가 Bowlby에게 반박 하면서 Robertson을 옹호하는 듯한 표현을 쓴 것도 Bowlby 와 Robertson의 사이를 멀어지게 만들었다. 이후 1964년 Robertson이 기획한 '단기간 분리된 어린아이' 프로젝트는 오히려 Anna Freud의 입장을 대변하기 위한 것처럼 보였다. 이 연구에서 그는 대리모가 있다면 엄마와 분리된 아이가 받 는 압박이 그다지 심하지 않을 수 있다는 결과를 도출함으로 써, Bowlby의 이전 연구 결과는 잘못이라고 결론지었다 (Robertson과 Robertson 1971).

일부 정신분석 역사학자들은 정신분석 이론의 태동기부터 정상 발달에 대한 이론이 부족하였던 점도 Bowlby의 퇴출과 관련 있을 것으로 추정하였다(Cortina와 Marrone 2004). Bowlby가 분석가로서 입문할 당시 유럽의 분석학계에서는 오랜 기간 동안 아동 학대와 방치 같은 현실을 충분히 고려 하지 않는 경향이 있었다. 그 이유는 학계를 주도하고 있던 Sigmund Freud와 Melanie Klein의 영향 때문이라고 추측 하였다. Sigmund Freud의 경우, 그의 어머니는 죽은 자기 남동생 Julius의 이름을 Sigmund Freud의 남동생에게 붙였 다. Freud의 남동생 역시 어릴 때 사망하면서 그의 어머니는 애도반응을 보였다. Sigmund Freud가 두 살 반 무렵, 유모가 떠났고(도둑질로 감옥행), 동생들이 연이어 출생하였으며, 아버지 사업 실패로 Fraiberg에서 Vienna 빈촌으로 이사하는 등 어린 시절에 이별과 상실 등의 외상을 경험하였다. Melanie Klein의 경우도 어릴 적부터 의사가 되려고 하였으나 아 버지의 경제적 몰락으로 포기하는 등 상실 경험이 있었으며, 우울증 성향도 있었다. 이 같은 개인력 때문에 Freud나 Klein 모두 영유아기 관련 탐색을 무의식적으로 배척했을 것이며, 아기와 엄마의 정상 발달 관련 이론인 애착이론을 거부했을 가능성도 제기되고 있다(Cortina와 Marrone 2004).

\section{분석이론과 애착이론의 수렴}

오래 전 연구자 사이의 견해 차이와 연구 주도 인물들 간의 갈등 때문에 결별하였으나, 후대의 신진 연구자들과 분석가 들 사이에 접점을 찾는 노력이 시작되었다(Fonagy와 Target 2003). 새로운 움직임이 일어나는 이유에 대해 몇 가지 중대 한 변화를 들 수 있다. 먼저, 애착 이론의 관찰 및 근거 중심 적 자료가 과학자들에게 잘 수용되고 있다. 둘째, 각 학파 간 주도권이 허물어지고 있다. 특히 미국에서 더하다. 셋째, 새 로운 이론적 틀을 수용할 만한 변화가 필요하다. 특히 정신 분석학계의 관심을 끌고 있는 것은 애착 및 발달이론가들의 유아관찰 연구 결과들이다(Zepf 2006). 
여전히 분석가 중 일부는 애착이론에 대한 문제점을 지적 하고 부정적 시각을 보이기도 하지만, 이러한 불협화음은 학 파 간 오해와 시대에 뒤처진 인식론적 차이에 의한 것이며 충분히 극복할 수 있다(Fonagy 2001). 특히 정신분석 이론 에 애착 관련 개념이 전혀 없었던 것은 아니라는 주장도 있 다. 정신분석 초기 이론에서는 아기와 어머니와의 관계는 아 기의 배고픔을 달래주는 어머니의 유방에 달려있다고 하였 고, 정서적 관계에 대한 언급을 거의 찾아볼 수 없다. 그러 나, Sigmund Freud는 말년에 어머니의 존재에 대하여 새로 운 견해를 피력한 바 있다(Karen 1998). "어머니란 평생 변 치 않는 독특하고 견줄 데 없는 최초이자 가장 강력한 사랑 의 대상(love object)이며, 훗날 남녀 모두 사랑하는 이와의 관계의 원형(prototype)이 된다(Freud 1940)." 애착이론에서 도 유아기의 애착 경험은 훗날 사랑 관계의 주 영향 인자라 고 가정한다는 점에서 애착이론과 정신분석 이론 사이에 공 통분모가 된다. Bowlby는 아기의 초기 경험의 중요성에 관 한 Sigmund Freud의 통찰력을 존중하였으며, 자신과 타인 의 내부작동모델이 원래 애착 인물과의 상호작용에서 구성 될 것으로 제시함으로써 초기 경험과 훗날 감정, 인지, 행동 사이의 연결고리에서 파생될 수 있는 정신분석 이론이 담고 있는 궁금증을 해결하였다(Owens 등 1995).

더구나 인식론적으로도 정신분석이론과 애착이론은 몇 가지 겹치는 부분이 있음을 강조한다(Fonagy 2001). 첫째, 사회적 지각과 사회 경험은 기대치에 따른 왜곡이 있으며, 둘째, 생후 첫 수년은 인격발달에 가장 중요한 시기이고, 셋 째, 어머니의 민감성은 대상 관계, 즉, 정신기능 발달의 질을 결정하는 요인이고, 넷째, 아기와 양육자의 관계는 관계를 위한 독립된 필요성에 기초한다. 이러한 두 이론 사이의 화 합 분위기가 유지, 확대되도록 하기 위해서는 갈등의 발단이 되었던 부분들에 대한 타협과 이해가 필요하며, 서로의 이론 을 통합하여 환자 치료에 도움이 되는 방향으로 발전시키는 노력이 필요하다. 이와 같은 작업은 정신분석 수련 기관에서 피교육생들에게도 전파되어야 할 것이다(Cortina 2016). 애 착이론은 물론, 영유아 연구와 기타 발달심리학에 대한 내용 이 정신분석 수련 교육 내용에 포함되어야 한다. 또한 인지, 정서, 동기, 상상, 기억, 의식과 무의식 경과 등의 신경과학 및 최신 마음 모델에 관한 내용도 포함해야 한다.

최근 van der Horst 등(2007)은 Ainsworth의 주요 업적 중 하나로 자기 제자들이 애착 연구 발전에 기여할 수 있도록 북돋아주는 안전기지 역할을 한 것을 들었고, 본 논문의 저 자도 전적으로 동의하는 바이다. 앞으로 애착이론과 정신분 석의 수렴과정이 계속 진행되기 위해서도 그러한 안전기지 가 필요할 것이다.

\section{결 론}

Bowlby의 애착이론은 기존의 정신분석 이론을 토대로 하 였으나, 관찰과 참여를 통한 근거중심적 접근법을 추가하였 다. 기존 정신분석은 개인의 내적 정신세계를 분석 대상으로 하였으나, 애착이론에서는 개인 간 상호작용을 분석 대상으 로 하는 점에서 차이가 있다. 애착발달은 영유아는 물론 그 부모와 일반 성인의 대인관계 결정에도 영향을 미친다. 이론 상 차이로 인해 멀어졌던 분석가들은 시대적 변화와 서로의 필요에 의해 소통하고 교류하기 시작하였다. 정신분석이론 과 애착이론의 수렴이 신진 연구자와 치료자의 교육은 물론, 임상 현장에서 환자를 더 잘 이해하고 도와줄 수 있는 치료 기법의 개발로 이어지기를 기대한다.

\section{Acknowledgments}

None

\section{Conflicts of Interest}

The author has no potential conflicts of interest to disclose.

\section{ORCID iD}

Geon Ho Bahn https://orcid.org/0000-0002-3550-0422

\section{REFERENCES}

Ainsworth MDS. Infancy in Uganda: infant care and the growth of love. Baltimore, MD: Johns Hopkins Press; 1967.

Ainsworth MDS, Andry RG, Harlow RG, Lebovici S, Mead M, Prugh DG, et al. Deprivation of maternal care: a reassessment of its effects. Geneva: World Health Organization;1962.

Ainsworth MDS, Blehar MC, Waters E, Wall SN. Patterns of attachment: a psychological study of the strange situation. Hillsdale, NJ: Erlbaum; 1978

Bahn GH. From attachment theory to mentalization: historical background and clinical implications. Psychoanal 2013;24:9-20.

Bahn GH. Margaret Mahler and the modern implication of separation-individuation theory. Psychoanal 2021;32:1-10.

Bemporad JR. From attachment to affiliation. Am J Psychoanal 1984;44: 79-92.

Bowlby J. Forty-four juvenile thieves: their characters and home-life. Int J Psychoanal 1944;25:19-52.

Bowlby J. Maternal care and mental health (Vol. 2). Geneva: World Health Organization; 1951.

Bowlby J. Grief and mourning in infancy and early childhood. Psychoanal Study Child 1960;15:9-52.

Bowlby J. Attachment and loss, vol. 1: attachment. New York, NY: Basic Books; 1969.

Bowlby J. Attachment and loss, vol. 2: separation: anxiety and anger. New York, NY: Basic Books;1973.

Bowlby J. A secure base: clinical applications of attachment theory. London: Routledge; 1988.

Cortina M. Quo vadis? The future of psychoanalysis. Psychoanal Rev 2016;103:793-817.

Cortina M, Marrone M. Reclaiming Bowlby's contribution to psychoanalysis. Int Forum Psychoanal 2004;13:133-146.

de Maat S, de Jonghe F, de Kraker R, Leichsenring F, Abbass A, Luyten P, et al. The current state of the empirical evidence for psychoanalysis: 
a meta-analytic approach. Harv Rev Psychiatry 2013;21:107-137.

Feeney JA, Noller P. Adult attachment. Thousand Oaks, CA: Sage;1996.

Fonagy P, Target M. Psychoanalytic theories: perspectives from developmental psychopathology. New York, NY: Routledge;2003. p.230-254.

Freud A. Discussion of Dr. John Bowlby's paper. Psychoanal Study Child 1960;15:53-62.

Freud A. Infants without families: reports on the Hampstead nurseries, 1939-1945. The writings of Anna Freud, vol. 3. New York, NY: International Universities Press; 1973.

Freud S. An outline of psychoanalysis. Int J Psychoanal 1940;21:27-84.

Freud S. An outline of psychoanalysis. In: Strachey J, editor and translator. The standard edition of the complete psychological works of Sigmund Freud (vol 23). London: Hogarth;1940.

Hargreaves GR. Obituary. Br Med J 1963;1:62-63.

Holmes J. John Bowlby and attachment theory. New York, NY: Routledge; 1993.

Karen R. Becoming attached: first relationships and how they shape our capacity to love. New York, NY: Oxford University Press;1998.

Lindsay M. Joyce Robertson obituary. [updated 2013 May 19; cited 2021 May 10]. Available from: https://www.theguardian.com/society/2013/ may/19/joyce-robertson.

Lorenz K. Der kumpan in der umwelt des vogels. J Ornithol 1935;83:137215, 289-413.

Main M, Solomon J. Procedures for identifying infants as disorganized/ disoriented during the Ainsworth Strange Situation. In: Greenberg MT, Cicchetti D, Cummings EM. Attachment during the preschool years: theory, research and intervention. Chicago, IL: University of Chicago Press;1990. p.121-160.

Owens G, Crowell JA, Pan H, Treboux D, O'Connor E, Waters E. The prototype hypothesis and the origins of attachment working models: adult relationships with parents and romantic partners. Monogr Soc Res Child Dev 1995;60:216-233.

Paris J. Is psychoanalysis still relevant to psychiatry? Can J Psychiatry
2017;62:308-312

Robertson J. A two-year-old goes to hospital [Film]. London: Tavistock Child Development Research Unit; 1952.

Robertson J, Robertson J. Young children in brief separation. A fresh look. Psychoanal Study Child 1971;26:264-315.

Schur M. Discussion of Dr. John Bowlby's paper. Psychoanal Study Child 1960;15:63-84.

Spitz R. Discussion of Dr. John Bowlby's paper. Psychoanal Study Child 1960;15:85-94.

Suomi SJ, van der Horst FCP, van der Veer R. Rigorous experiments on monkey love: an account of Harry F. Harlow's role in the history of attachment theory. Integr Psychol Behav Sci 2008;42:354-369.

Thombs BD, Jewett LR, Bassel M. Is there room for criticism of studies of psychodynamic psychotherapy? Am Psychol 2011;66:148-149.

van der Horst FC, Leroy HA, van der Veer R. "When strangers meet": John Bowlby and Harry Harlow on attachment behavior. Integr Psychol Behav Sci 2008;42:370-388.

van der Horst FCP, Zetterqvist Nelson $K$, van Rosmalen $L$, van der Veer R. A tale of four countries: how Bowlby used his trip through Europe to write the WHO report and spread his ideas. J Hist Behav Sci 2020;56:169-185

van der Horst FCP, van der Veer R. Separation and divergence: the untold story of James Robertson's and John Bowlby's theoretical dispute on mother-child separation. J Hist Behav Sci 2009;45:236-252.

van der Horst FCP, van der Veer R, van Ijzendoorn MH. John Bowlby and ethology: an annotated interview with Robert Hinde. Attach Hum Dev 2007;9:321-335.

van Rosmalen L, van der Veer R, van der Horst FCP. The nature of love: Harlow, Bowlby and Bettelheim on affectionless mothers. Hist Psychiatry 2020;31:227-231.

Zepf S. Attachment theory and psychoanalysis: some remarks from an epistemological and from a Freudian viewpoint. Int J Psychoanal 2006;87:1529-1548 